\title{
Abnormal essential fatty acid composition of tissue lipids in genetically diabetic mice is partially corrected by dietary linoleic and $\gamma$-linolenic acids
}

\author{
BY S. C. CUNNANE, M. S. MANKU AND D. F. HORROBIN \\ Efamol Research Institute, PO Box 818, Kentville, Nova Scotia, Canada B4N $4 H 8$
}

(Received 29 February 1984 - Accepted 26 November 1984)

1. Genetically diabetic mice $(d b / d b)$ and their non-diabetic litter-mates were maintained for 15 weeks on diets supplemented with safflower oil or evening primrose (Oenothera bienis) oil, both essential fatty acid (EFA)-rich sources, or hydrogenated coconut oil (devoid of EFA).

2. Plasma glucose was higher in the diabetic mice supplemented with the oils than in the unsupplemented diabetic mice. In the oil-supplemented non-diabetic mice, plasma glucose did not differ compared with the unsupplemented non-diabetic mice.

3. The proportional content of arachidonic acid in the phospholipids of the pancreas was significantly decreased in diabetic mice, an effect which was completely prevented by supplementation with safflower or evening primrose oil but not hydrogenated coconut oil.

4. In the liver phospholipids of the diabetic mice, dihomo- $\gamma$-linolenic acid was proportionally increased, an effect reduced by supplementation with safflower oil but not evening primrose or hydrogenated coconut oils.

5. In the liver triglycerides of the diabetic mice, $\gamma$-linolenic acid, dihomo- $\gamma$-linolenic acid and arachidonic acid were all proportionally decreased, effects which were also prevented by safflower or evening primrose oil but not hydrogenated coconut oil.

6. Alopecia and dry scaly skin were prominent in the diabetic mice but less extensive in the diabetic mice supplemented with EFA.

In C57BL/KsJ mice, homozygous inheritance of the $d b$ gene confers the features of obesity, hyperglycemia and hyperinsulinemia (Coleman \& Hummel, 1967; Coleman, 1981). This condition has been likened to non-insulin dependent (Type II) or maturity-onset diabetes in humans. Insulin secretion in the diabetic mouse is excessive initially and decreases towards normal after 3-4 months of age. Although increased peripheral resistance to the actions of insulin is generally considered to be the reason for increased insulin secretion, the cause of the insulin resistance has not been resolved.

The essential fatty acids (EFA) are long-chain polyunsaturated fatty acids belonging to two families; those of which linoleic acid $(18: 2 n-6)$ is the precursor, or those of which $\alpha$-linolenic acid (18:3n-3) is the precursor. Arachidonic acid (20:4n-6) incorporation into pancreatic islet phospholipids is considered to be an important step in the initiation of insulin secretion (Laychock, 1983). The level of 20:4n-6 has been shown to be decreased in the retinal vasculature (Futterman \& Kupfer, 1968) and platelets (Houtsmuller et al. 1980; Jones et al. 1983) of diabetic humans. In human adult-onset diabetes, dietary supplementation with $18: 2 \mathrm{n}-6$ has been shown to reduce the incidence of retinal angiopathy (Poisson, 1978; Houtsmuller et al. 1981).

In the rat models of insulin-dependent diabetes (alloxan or streptozotocin injection), desaturation of $18: 2 \mathrm{n}-6$ has been shown to be decreased in various tissues (Mercuri et al. 1966; De Alaniz \& Brenner, 1969; Faas \& Carter, 1980, 1983; Clark et al. 1983; Holman et al. 1983). 20:4n-6 has also been reported to prevent testicular atrophy in alloxan-diabetic rats (Brenner et al. 1968). However, the EFA composition of the tissues of genetically diabetic mice or their response to supplemental dietary EFA has not, to our knowledge, been described. We have reported abnormalities in the EFA composition of liver and adipose tissue in genetically obese mice (Cunnane $e t$ al. 1985). Since genetically diabetic mice 
Table 1. Fatty acid composition ( $\mathrm{mg} / \mathrm{g}$ total fatty acids) of hydrogenated coconut oil (HCO), safflower oil (SFO), evening primrose oil (EPO) and the diets supplemented with these oils

\begin{tabular}{|c|c|c|c|c|c|c|c|}
\hline \multirow[b]{2}{*}{ Fatty acid } & \multicolumn{3}{|c|}{ Oil } & \multicolumn{4}{|c|}{ Diet } \\
\hline & $\mathrm{HCO}$ & SFO & EPO & CTL* $^{*}$ & $\mathrm{HCO}$ & SFO & EPO \\
\hline $8: 0$ & 70 & - & - & - & 21 & - & - \\
\hline $10: 0$ & 60 & - & - & - & 33 & - & - \\
\hline $12: 0$ & 460 & - & - & - & 280 & - & - \\
\hline $14: 0$ & 185 & - & - & - & 116 & _- & - \\
\hline $16: 0$ & 94 & 72 & 63 & 201 & 141 & 126 & 142 \\
\hline $16: 1 n-7$ & - & 2 & 1 & 31 & 15 & 15 & 19 \\
\hline $18: 0$ & 111 & 21 & 17 & 87 & 98 & 48 & 53 \\
\hline $18: \ln -9$ & 15 & 105 & 100 & 304 & 144 & 198 & 217 \\
\hline $18: 2 n-6$ & - & 786 & 727 & 274 & 122 & 569 & 458 \\
\hline $18: 3 n-6 \dagger$ & - & - & 91 & - & - & - & 38 \\
\hline $18: 3 n-3$ & - & 7 & - & 33 & 13 & 16 & 16 \\
\hline $20: 4 n-6$ & - & - & - & 10 & 4 & 5 & 6 \\
\hline $22: 6 n-3$ & - & - & - & 9 & 4 & 4 & 6 \\
\hline
\end{tabular}

* CTL, unsupplemented Purina chow.

$+18: 3 n-6$ has the same retention time as 20:0.

are phenotypically indistinguishable from genetically obese mice (Bar Harbor strains) and both have similar metabolic defects, it was also of interest to report our findings of tissue lipid fatty acid composition and response to EFA supplementation in genetically diabetic mice.

We have measured the levels of EFA in the tissues of genetically diabetic mice and also assessed the effect of dietary supplementation of these mice with safflower oil (SFO, $790 \mathrm{~g}$ $18: 2 \mathrm{n}-6 / \mathrm{kg}$ ), evening primrose oil (EPO, $720 \mathrm{~g} 18: 2 \mathrm{n}-6 / \mathrm{kg}$ and $90 \mathrm{~g} \gamma$-linolenic acid,

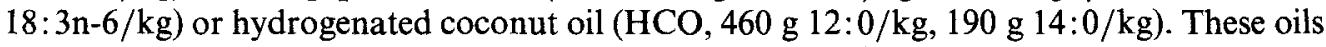
were tested because the conversion of $18: 2 \mathrm{n}-6$ to $18: 3 \mathrm{n}-6$ (via the $\delta$-6-desaturase) is considered the rate-limiting step in EFA metabolism (Brenner, 1977) and defects in this enzyme have been reported in animal models of diabetes. Hence a comparison of oils containing or lacking $\gamma$-linolenic acid may be informative about the activity of the $\delta$-6-desaturase in diabetic mice.

\section{METHODS}

Animals and diets

Genetically diabetic mice (C57BL/KsJ, $d b / d b)$ at 6 weeks of age were obtained from Jackson Laboratory (Bar Harbor, Maine, USA). Non-diabetic litter-mates $(d b /+m$ or $+m /+m$, misty) were used as controls. Both the diabetic mice and non-diabetic control mice were divided into four groups of five mice each. They were given Purina rodent chow meal (no. 5001) for 15 weeks and tap water ad lib. The four groups were: (1) control (unsupplemented), (2) $50 \mathrm{~g}$ hydrogenated coconut oil (HCO; Teklad Test Diets, Madison, $\mathrm{WN}$ ) $/ \mathrm{kg}$ chow, (3) $50 \mathrm{~g}$ safflower oil (SFO, commercial source) $/ \mathrm{kg}$ chow or (4) $50 \mathrm{~g}$ evening primrose oil (EPO, Efamol UK, Guildford, Surrey)/kg chow. The designations of these groups were: diabetic (CTL), non-diabetic (CTL), diabetic (HCO), non-diabetic (HCO), diabetic (SFO), non-diabetic (SFO), diabetic (EPO), non-diabetic (EPO).

The fatty acid composition of the supplemental oils and final diets is shown in Table 1. 
Following $24 \mathrm{~h}$ starvation, the mice were killed by diethyl ether anesthesia. Liver, pancreas, epididymal fat and skin samples were dissected, washed in saline ( $9 \mathrm{~g}$ sodium chloride/l) and frozen for lipid analysis. Plasma samples were used for glucose determinations.

\section{Histology}

Due to development of scaliness of the skin in the diabetic mice, at the end of the experiment skin samples from all the mice were fixed in formalin for histology. Sections were prepared by standard techniques.

\section{Glucose}

Plasma glucose was measured using an automated centrifugal analyser (COBAS BIO, Roche).

\section{Lipid extraction and fatty acid analysis}

All solvents used in these procedures were certified reagent grade. Tissue samples (approximately $1 \mathrm{~g}$ ) were homogenized (Polytron, Brinkmann Instruments) in $20 \mathrm{vol}$. chloroform-methanol $(2: 1, \mathrm{v} / \mathrm{v})$ containing $200 \mathrm{mg}$ butylated hydroxytoluene/ 1 as antioxidant. Triglycerides (TG) and total phospholipids (tPL) were separated by thin-layer chromatography on Merck 5765 silica gel G plates (BDH, Poole, Dorset) using the solvent system : light petroleum $\left(40-60^{\circ}\right)$-diethyl ether-acetic acid-methanol $(85: 15: 2 \cdot 5: 1$, by vol.). Silica bands containing the tPL and TG were scraped off the plates into screw-capped vials. The lipids were methylated with boron-trifluoride (Chromatographic Specialities, Brockville, Ontario) at $70^{\circ}$ for $30 \mathrm{~min}$. The fatty acid methyl esters were extracted with hexane and analysed by gas-liquid chromatography (Hewlett Packard model 5880) using a $2 \mathrm{~m}$ glass column packed with 10\% silar-10C on Gas Chrom Q 100/120 (Applied Science Division, State College, PA). The carrier gas was helium $(30 \mathrm{ml} / \mathrm{min})$. The oven temperature was programmed to rise from $165^{\circ}$ to $190^{\circ}$ at the rate of $2^{\circ} / \mathrm{min}$. The detector temperature was set at $220^{\circ}$. Retention times and peak areas were automatically computed by an integrator (level 4, Hewlett Packard). Fatty acid peaks were identified by comparison with standard fatty acid methyl esters (Nu-Chek Prep, Elysian, MN).

Extraction of lipids from the skin required saponification of the total lipids to release the free fatty acids which were then quantified by gas-liquid chromatography. This was achieved by dissolving the samples in methanolic potassium hydroxide at $90^{\circ}$ for $90 \mathrm{~min}$. The non-saponified material was extracted into hexane and discarded. The saponifiable material containing the fatty acids of interest was acidified to $\mathrm{pH} \mathrm{1-2} \mathrm{and} \mathrm{the} \mathrm{fatty} \mathrm{acids}$ extracted with hexane, methylated and quantified as described previously.

\section{Statistics}

Two-way analysis of variance (ANOVA) and Student's $t$ test were used for statistical comparisons.

\section{RESULTS}

\section{Glucose}

Individual samples from the mice in each group were pooled for glucose assays. The values for glucose between groups have thus not been compared statistically. Glucose in the plasma of the diabetic mice was higher than in the non-diabetic control mice $(4.7 v .1 .9 \mathrm{~g} / 1)$. Supplementation with HCO, SFO or EPO had no effect on plasma glucose in the non-diabetic mice but increased plasma glucose by about $40 \%(\mathrm{HCO})$ and $60 \%$ (SFO, EPO) in the diabetic mice. 
Table 2. Long chain, non-essential fatty acid composition ( $\mathrm{mg} / \mathrm{g}$ total fatty acids) of pancreas total phospholipids $(t P L)$, liver $t P L$ and liver triglycerides $(T G)$ from diabetic $(D B)$ and non-diabetic (ND) mice given Purina rodent chow (unsupplemented)

(Values are means and standard deviations for five samples)

\begin{tabular}{|c|c|c|c|c|c|c|c|c|}
\hline \multirow[t]{2}{*}{ Fatty acid... } & \multicolumn{2}{|c|}{$16: 0$} & \multicolumn{2}{|c|}{$16: \ln -7$} & \multicolumn{2}{|c|}{$18: 0$} & \multicolumn{2}{|c|}{$18: \ln -9$} \\
\hline & Mean & SD & Mean & SD & Mean & sD & Mean & SD \\
\hline \multicolumn{9}{|l|}{ Pancreas tPL } \\
\hline DB & 185 & 22 & 14 & 5 & 92 & 15 & 156 & 26 \\
\hline ND & 189 & 9 & 14 & 2 & 105 & 29 & $117^{* * *}$ & 12 \\
\hline \multicolumn{9}{|l|}{ Liver tPL } \\
\hline DB & 182 & 18 & 8 & 3 & 180 & 64 & 81 & 17 \\
\hline ND & $236^{* *}$ & 23 & 12 & 3 & $109^{*}$ & 40 & 91 & 14 \\
\hline \multicolumn{9}{|l|}{ Liver TG } \\
\hline DB & 225 & 10 & 75 & 16 & 19 & 4 & 379 & 70 \\
\hline ND & $274^{* *}$ & 19 & 63 & 17 & 19 & 7 & 323 & 26 \\
\hline
\end{tabular}

Mean values for DB and ND were significantly different (Student's $t$ test): ${ }^{*} P<0.05,{ }^{* *} P<0.01$.

\section{Body-weights and tissue weights}

After 15 weeks the diabetic (CTL) mice weighed twice as much as the non-diabetic (CTL) mice (53.6v. 27.0 g, $P<0.01$ ). Because of a wide variation in the final body-weights, the trend to lower body-weights in the diabetic (SFO) and diabetic (EPO) mice was not significant compared with the diabetic (CTL) mice. This was due to the fact that some diabetic mice started to lose weight as early as 5 weeks into the experiment (11 weeks of age) while others continued to gain weight rapidly throughout the experiment. Supplemental HCO, SFO and EPO had no effect on final body-weight in the non-diabetic mice. Food intake varied between mice both within and between groups but, overall, was not significantly different between groups of diabetic or non-diabetic mice (results not shown). By the end of the experiment both diabetic and non-diabetic mice had stopped gaining weight.

Liver weights in the diabetic (CTL) mice were twice those of the non-diabetic (CTL) mice $(2.9$ v. $1.4 \mathrm{~g}, P<0.01)$ but were not different between the groups of diabetic mice. In the diabetic (CTL) mice, the testes were smaller than in the non-diabetic (CTL) mice $(0.9 v$. $1.5 \mathrm{~g}, P<0.01$ ). The epididymal fat pad was nearly three times as large in the diabetic (CTL) as in the non-diabetic (CTL) mice $(1.3 v .0 .5 \mathrm{~g}, P<0.01)$. The weight of the epididymal fat pad was significantly increased in the non-diabetic (HCO) and (SFO) mice compared with that of the non-diabetic (CTL) mice. Otherwise there were no significant differences in the organ weights of the diabetic or non-diabetic mice supplemented with $\mathrm{HCO}$, SFO or EPO.

\section{Skin histology}

After the 10th week of the experiment it was noted that the skin in the scapular to mid-dorsal region of the diabetic mice became scaly and hair fell out of the affected area. No inflammation, infection or exudate was observed in any of the affected mice. The diabetic (HCO) mice were most affected; hair loss extended from the back of the head to include most of the back. Histologically the dermis of the skin of the diabetic mice was much thinner than that of the non-diabetic mice (see Plate 1). Although the alopecia and scaliness were 
Table 3. Essential fatty acid composition $(\mathrm{mg} / \mathrm{g}$ total fatty acids) of pancreas total phospholipids from diabetic $(D B)$ and non-diabetic $(N D)$ mice given an unsupplemented chow $(C T L)$, or chow supplemented with hydrogenated coconut oil $(H C O)$, safflower oil (SFO) or evening primrose oil (EPO)

(Values are means and standard deviations for five samples)

\begin{tabular}{|c|c|c|c|c|c|c|c|c|c|}
\hline \multirow{2}{*}{\multicolumn{2}{|c|}{$\begin{array}{l}\text { Diet... } \\
\text { Fatty acid }\end{array}$}} & \multicolumn{2}{|c|}{ CTL } & \multicolumn{2}{|c|}{$\mathrm{HCO}$} & \multicolumn{2}{|c|}{ SFO } & \multicolumn{2}{|c|}{ EPO } \\
\hline & & \multirow{2}{*}{$\begin{array}{c}\text { Mean } \\
259\end{array}$} & \multirow{2}{*}{$\frac{S D}{17}$} & \multirow{2}{*}{$\frac{\text { Mean }}{301}$} & \multirow{2}{*}{$\frac{S D}{43}$} & \multirow{2}{*}{$\frac{\text { Mean }}{334}$} & \multirow{2}{*}{$\begin{array}{l}\text { SD } \\
80\end{array}$} & \multirow{2}{*}{$\frac{\text { Mean }}{314^{* *}}$} & \multirow{2}{*}{$\frac{\text { SD }}{35}$} \\
\hline $18: 2 n-6$ & DB & & & & & & & & \\
\hline & $\mathrm{ND+}+$ & 264 & 36 & 223 & 9 & 288 & 17 & 278 & 16 \\
\hline \multirow[t]{2}{*}{$20: 4 n-6$} & DB & 119 & 5 & 126 & 5 & $141^{* *}$ & 16 & $164^{* *}$ & 18 \\
\hline & $\mathrm{ND}^{+\dagger}$ & 156 & 12 & 162 & 13 & $183^{* * *}$ & 11 & $227^{* *}$ & 20 \\
\hline \multirow[t]{2}{*}{$22: 4 n-6$} & DB & 8 & 2 & 9 & 4 & 8 & 2 & 5 & 2 \\
\hline & ND & 6 & 1 & 7 & 2 & $8^{*}$ & 1 & 8 & 1 \\
\hline \multirow[t]{2}{*}{$22: 5 n-6$} & DB & $\operatorname{Tr}$ & & $\mathrm{Tr}$ & & $\operatorname{Tr}$ & & $11^{* *}$ & 2 \\
\hline & ND & 3 & I & 3 & 1 & 4 & 0.4 & 4 & 1 \\
\hline \multirow[t]{2}{*}{$18: 3 n-3$} & DB & 5 & 1 & 5 & 1 & 4 & 1 & $3^{* *}$ & 0.3 \\
\hline & ND & 5 & 1 & 4 & 1 & $8^{* *}$ & 2 & $8^{* *}$ & 2 \\
\hline \multirow[t]{2}{*}{$22: 5 n-3$} & DB & 19 & 3 & 17 & 4 & 17 & 4 & $\mathrm{Tr}_{\mathrm{r}}^{* *}$ & \\
\hline & $\mathrm{ND}+{ }^{\dagger}$ & 8 & 0.4 & 9 & 1 & 7 & 1 & 6 & 1 \\
\hline \multirow[t]{2}{*}{$22: 6 n-3$} & DB & 76 & 9 & 72 & 10 & 69 & 3 & 12 & 1 \\
\hline & $\mathrm{ND}+{ }^{+}$ & 81 & 13 & 88 & 8 & 79 & 8 & 82 & 6 \\
\hline
\end{tabular}

$\operatorname{Tr}$, trace amount detected $(<1 \mathrm{mg} / \mathrm{g})$.

Mean values for $\mathrm{HCO}, \mathrm{SFO}$ and EPO were significantly different from CTL in both DB and ND mice (ANOVA and Student's $t$ test): ${ }^{*} P<0.05,{ }^{* *} P<0.01$.

Mean values for DB and ND groups as a whole were significantly different (ANOVA): $\dagger \dagger P<0.01$.

subjectively rated as being less severe in the diabetic (SFO) and (EPO) groups than in the diabetic (CTL) or (HCO) groups, histologically the four groups appeared similar. Therefore, although the type of lesion was apparently similar in all four groups, it was less extensive in those diabetic mice supplemented with EFA.

\section{Tissue fatty acid composition}

The analyses in Tables 2-6 are of the proportional composition of the long-chain fatty acids in the tissue lipids, i.e. they indicate changes in the concentration of the individual fatty acids in the various lipid fractions.

The proportional composition of the long-chain non-EFA $(16: 0,16: 1 \mathrm{n}-7,18: 0,18: 1 \mathrm{n}-9)$ in pancreas tPL, liver tPL and liver TG have been grouped into Table 2 . This has been done because only minor differences existed between diabetic and non-diabetic mice and because effects of dietary supplementation on these fatty acids were substantially the same for each lipid fraction analysed; EFA supplementation proportionally decreased $16: 1 \mathrm{n}-7$ and 18: $1 \mathrm{n}-9$ but did not affect 16:0 or 18:0.

Pancreas $t P L$. Proportionally, $18: 2 \mathrm{n}-6$ was not significantly different in the pancreas $t P L$ of the diabetic (CTL) or non-diabetic (CTL) mice; however, EFA supplementation significantly increased the proportional composition of $18: 2 n-6$ in diabetic but not nondiabetic mice (Table 3).

Effects of diabetes or diet on 18:3n-6 and 20:3n-6 were not significant (results not shown). 20:4n-6 and 22:5n-6 were proportionally lower in the diabetic (CTL) mice but, in diabetic (EPO) mice, both increased to levels higher than in the non-diabetics. $22: 4 n-6$ was higher 
Table 4. Essential fatty acid composition ( $\mathrm{mg} / \mathrm{g}$ total fatty acids) of liver total phospholipids from diabetic $(D B)$ and non-diabetic $(N D)$ mice given unsupplemented rodent chow $(C T L)$ or chow supplemented with $50 \mathrm{~g}$ hydrogenated coconut oil $/ \mathrm{kg}(\mathrm{HCO}), 50 \mathrm{~g}$ safflower oil $/ \mathrm{kg}(\mathrm{SFO})$ or $50 \mathrm{~g}$ evening primrose oil $/ \mathrm{kg}(E P O)$

(Values are means and standard deviations for five samples)

\begin{tabular}{|c|c|c|c|c|c|c|c|c|c|}
\hline \multirow{2}{*}{$\begin{array}{l}\text { Diet... } \\
\text { Fatty acid }\end{array}$} & & \multicolumn{2}{|c|}{ CTL } & \multicolumn{2}{|c|}{$\mathrm{HCO}$} & \multicolumn{2}{|c|}{ SFO } & \multicolumn{2}{|c|}{ EPO } \\
\hline & & Mean & SD & Mean & $\mathrm{SD}$ & Mean & SD & Mean & SD \\
\hline \multirow[t]{2}{*}{$18: 2 n-6$} & DB & 161 & 16 & 180 & 16 & $218^{* *}$ & 18 & $181^{*}$ & 22 \\
\hline & ND+† & 162 & 24 & 155 & 21 & 181 & 8 & 172 & 3 \\
\hline \multirow{2}{*}{$18: 3 n-6 \ddagger$} & DB & $\operatorname{Tr}$ & & $\operatorname{Tr}$ & & $\operatorname{Tr}$ & & $3^{* *}$ & 0.4 \\
\hline & ND & 1 & 0.1 & 1 & 0.1 & 2 & 2 & $6^{* *}$ & 1 \\
\hline \multirow[t]{2}{*}{$20: 3 n-6$} & DB & 26 & 3 & $22^{* *}$ & 2 & $17^{* *}$ & 3 & 25 & 4 \\
\hline & ND+t & 18 & 1 & 14 & 2 & 17 & 1 & $21^{* *}$ & 1 \\
\hline \multirow[t]{2}{*}{$20: 4 n-6$} & DB & 174 & 3 & 166 & 22 & 206 & 27 & 216 & 45 \\
\hline & $\mathrm{ND}+\uparrow$ & 160 & 25 & 145 & 16 & 175 & 8 & $197^{*}$ & 13 \\
\hline \multirow[t]{2}{*}{$18: 3 n-3$} & DB & $\operatorname{Tr}$ & & $1^{* *}$ & $0 \cdot 1$ & $\operatorname{Tr}$ & & $\mathrm{Tr}$ & \\
\hline & ND & 4 & 0.1 & $3^{* *}$ & 0.5 & $3^{* *}$ & 0.4 & 2 & 0.5 \\
\hline \multirow[t]{2}{*}{$20: 5 n-3$} & DB & 22 & 11 & 19 & 8 & $4 * *$ & 1 & $3^{* *}$ & 1 \\
\hline & $\mathrm{ND}+\dagger$ & 13 & 5 & 9 & 1 & $2 * *$ & $0 \cdot 3$ & $1^{* *}$ & 0.3 \\
\hline \multirow[t]{2}{*}{$22: 6 n-3$} & DB & 151 & 27 & 159 & 29 & 132 & 8 & 136 & 14 \\
\hline & ND & 178 & 31 & 186 & 26 & $132^{*}$ & 2 & $129^{*}$ & 3 \\
\hline
\end{tabular}

Tr, trace amounts detected $(<1 \mathrm{mg} / \mathrm{g})$.

Mean values for $\mathrm{HCO}$, SFO and EPO were significantly different from CTL in both DB and ND mice (ANOVA and Student's $t$ test): ${ }^{*} P<0.05,{ }^{* *} P<0.01$.

Mean values for DB and ND mice as a whole were significantly different (ANOVA): $\dagger \dagger P<0.01$.

$\ddagger 18: 3 n-6$ has the same retention time as $20: 0$.

Table 5. Essential fatty acid composition $(\mathrm{mg} / \mathrm{g}$ total fatty acids) of liver triglycerides from diabetic $(D B)$ and non-diabetic $(N D)$ mice given unsupplemented rodent chow $(C T L)$ or chow supplemented with $50 \mathrm{~g}$ hydrogenated coconut oil $/ \mathrm{kg}$ (HCO), $50 \mathrm{~g}$ safflower oil $/ \mathrm{kg}(\mathrm{SFO})$ or $50 \mathrm{~g}$ evening primrose oil $/ \mathrm{kg}$ (EPO)

(Values are means and standard deviations for five samples)

\begin{tabular}{|c|c|c|c|c|c|c|c|c|c|}
\hline \multirow{2}{*}{$\begin{array}{l}\text { Diet... } \\
\text { Fatty acid }\end{array}$} & & \multicolumn{2}{|c|}{ CTL } & \multicolumn{2}{|c|}{$\mathrm{HCO}$} & \multicolumn{2}{|c|}{ SFO } & \multicolumn{2}{|c|}{ EPO } \\
\hline & & Mean & SD & Mean & SD & Mean & SD & Mean & SD \\
\hline \multirow[t]{2}{*}{$18: 2 n-6$} & DB & 224 & 80 & 192 & 31 & $447^{* *}$ & 21 & $443^{* *}$ & 58 \\
\hline & ND & 234 & 37 & 210 & 31 & $388 * *$ & 23 & $411^{* *}$ & 19 \\
\hline \multirow[t]{2}{*}{$18: 3 n-6+$} & DB & 5 & 4 & 4 & 1 & 6 & 1 & $13^{* *}$ & 1 \\
\hline & ND+† & 10 & 1 & 9 & 2 & 9 & 1 & $17^{* *}$ & 4 \\
\hline \multirow[t]{2}{*}{$20: 3 n-6$} & DB & 3 & 1 & 4 & 1 & $11^{* *}$ & 1 & $20^{* *}$ & 4 \\
\hline & ND & 7 & 1 & 7 & 1 & 9 & 1 & $15^{* *}$ & 1 \\
\hline \multirow[t]{2}{*}{$20: 4 n-6$} & DB & 9 & 6 & 8 & 2 & $15 * *$ & 2 & $21^{* *}$ & 2 \\
\hline & NDt† & 15 & 4 & 18 & 4 & 17 & 2 & $23^{* *}$ & 2 \\
\hline \multirow[t]{2}{*}{$18: 3 n-3$} & DB & 15 & 3 & 17 & 2 & 13 & 1 & 13 & 1 \\
\hline & $\mathrm{ND}+\dagger$ & 19 & 2 & 19 & 2 & $11^{* *}$ & 1 & $10^{* *}$ & 1 \\
\hline \multirow[t]{2}{*}{$22: 6 n-3$} & DB & 16 & 7 & 20 & 10 & $25^{*}$ & 4 & 23 & 5 \\
\hline & $\mathrm{ND}++$ & 32 & 9 & 39 & 10 & 19 & 3 & 22 & 3 \\
\hline
\end{tabular}

Mean values for HCO, SFO and EPO were significantly different from CTL in both DB and ND mice (ANOVA and Student's $t$ test): * $P<0.05, * * P<0.01$.

Mean values for DB and ND groups as a whole were significantly different (ANOVA): $\dagger+P<0 \cdot 01$.

$+18: 3 \mathrm{n}-6$ has the same retention time as $20: 0$. 
Table 6. Fatty acid composition ( $\mathrm{mg} / \mathrm{g}$ total fatty acids) of skin total lipids from diabetic (DB) and non-diabetic $(N D)$ mice given rodent chow

(Values are means and standard deviations for five samples)

\begin{tabular}{|c|c|c|c|c|}
\hline & \multicolumn{2}{|c|}{ DB } & \multicolumn{2}{|c|}{ ND } \\
\hline Fatty acid & Mean & $\mathrm{SD}$ & Mean & SD \\
\hline $16: 0$ & 222 & 9 & $195^{* *}$ & 8 \\
\hline $16: \ln -7$ & 72 & 7 & $92^{* *}$ & 7 \\
\hline $18: 0$ & 32 & 4 & $27^{*}$ & 3 \\
\hline $18: 1 n-9$ & 425 & 18 & 414 & 14 \\
\hline $18: 2 \mathrm{n}-6$ & 235 & 9 & 241 & 8 \\
\hline $20: 4 n-6$ & $\operatorname{Tr}$ & - & $4^{* *}$ & 0.2 \\
\hline $18: 3 n-3$ & 14 & 1 & $20^{* *}$ & 1 \\
\hline
\end{tabular}

$\mathrm{Tr}$, trace amounts detected $(<1 \mathrm{mg} / \mathrm{g})$.

Mean values for DB and ND were significantly different (Student's $t$ test): ${ }^{*} P<0 \cdot 05,{ }^{* *} P<0 \cdot 01$.

in the diabetic (CTL) than in the non-diabetic (CTL) mice, an effect reversed in the diabetic (EPO) mice.

$18: 3 n-3$ was proportionally increased in the non-diabetic (EPO) compared with non-diabetic (CTL) mice, but the reverse occurred in the diabetic mice. The proportional composition of $22: 5 n-3$ and $22: 6 n-3$ was significantly decreased in the diabetic (EPO) compared with diabetic (CTL) mice but was not significantly changed in the non-diabetic mice supplemented with EFA (Table 3).

Liver $t P L$. In the liver $\mathrm{TL}$, the proportional composition of $18: 2 \mathrm{n}-6$ increased significantly more in the diabetic (EPO) than non-diabetic (EPO) mice (Table 4). Proportional composition of $20: 3 n-6$ was significantly higher in the diabetic (CTL) than non-diabetic (CTL) mice; with EFA supplementation, this difference was eliminated. Compared with the non-diabetic mice, 20:4n-6 was proportionally higher in all of the groups of diabetic mice, a difference not affected by diet.

$18: 3 n-3$ was present in proportionally lower amounts in the diabetic than in the nondiabetic mice. Proportionally, more $20: 5 n-3$ was present in the liver tPL of diabetic (CTL) than non-diabetic (CTL) mice, a difference eliminated when comparing the diabetic and non-diabetic (EPO) mice (Table 4).

Liver TG. Compared with their respective CTL groups, a consistently larger increase in the proportion of n-6 EFA occurred in diabetic (EPO) compared with non-diabetic (EPO) mice. The n-3 EFA, $18: 3 n-3$ and $22: 6 n-\hat{3}$, decreased significantly less in diabetic than non-diabetic mice supplemented with EFA (Table 5).

Skin total lipids. The proportional composition of the saturated fatty acids was increased but EFA were decreased in the skin total lipids of the diabetic compared with the non-diabetic mice (Table 6).

Epididymal fat TG. As a percentage of the total, 16:0 was higher and 18:3n-3 lower in diabetic (CTL) compared with non-diabetic (CTL) mice. EFA supplementation significantly decreased $16: 1 n-7,18: \ln -9$ and $18: 3 n-3$, and increased $18: 2 n-6,18: 3 n-6$ and $20: 3 n-6$ in both the diabetic and non-diabetic mice (results not shown). 


\section{DISCUSSION}

In the tPL of the pancreas, 20:4n-6 was proportionally lower in the diabetic mice compared with the non-diabetic mice. This change was partially corrected in the diabetic (SFO) mice and was completely corrected in the diabetic (EPO) mice. Other differences in the percentage composition of n-6 EFA in the pancreas $(22: 4 n-6,22: 5 n-6)$ were also inhibited by the presence of EPO but not SFO in the diet (Table 3). Similar effects were seen in the tPL and TG of the liver (Tables 4 and 5).

The scaliness of the skin of the diabetic mice, which was marked in those mice supplemented with HCO, appeared to be reduced by SFO or EPO. Histologically, this difference was not observed. Our results therefore indicate that. compared with non-diabetic mice, proportional tissue EFA composition was significantly different in their diabetic litter-mates. A trend towards normalization of the EFA composition of affected tissues was observed after feeding diabetic mice supplementary EFA, particularly the combination of $18: 2 n-6$ and $18: 3 n-6$ found in EPO.

Although differences in fatty acid composition between the diabetic and non-diabetic mice were partially corrected, differences in blood glucose were enhanced by supplementation with the oils. HCO, SFO and EPO had similar effects in this respect so it would appear to be a non-specific fat effect.

Arachidonic acid has been shown to increase blood glucose significantly more in genetically obese mice of the same strain, used in the present experiment, than in white mice (Pratt, 1984). Enhanced proportional phospholipid content of arachidonic acid in the diabetic mice liver (Table 4) may therefore be a factor contributing to the hyperglycaemia of this strain of diabetic mouse.

The effect of diabetes on EFA composition and metabolism has generally been studied in insulin-dependent diabetic humans or animals. It is well-established that desaturation of $18: 2 n-6$ is impaired in insulin-dependent diabetic rats, causing low levels of $20: 4 n-6$ in various tissues (Mercuri et al. 1966). In the present study, the proportion of $20: 4 n-6$ in the pancreas tPL was lower in the diabetic (CTL) than in the non-diabetic (CTL) mice, suggesting a decrease in 18:2n-6 desaturation in the pancreas as seen in insulin-dependent diabetic rats (Mercuri et al. 1966). This was also supported in the present study by the effects of SFO and EPO in the diabetic mice (Table 3). In the diabetic mice supplemented with SFO $(790 \mathrm{~g} 18: 2 \mathrm{n}-6 / \mathrm{kg})$ the ratio, $18: 2 \mathrm{n}-6 /$ metabolites, was higher than in the non-diabetic (CTL) mice. In the non-diabetic (SFO) mice, this ratio was lower than in the non-diabetic (CTL) mice. Supplementation of the diabetic mice with EPO $(730 \mathrm{~g} 18: 2 \mathrm{n}-6 / \mathrm{kg}, 90 \mathrm{~g}$ $18: 3 \mathrm{n}-6 / \mathrm{kg}$ ) decreased $18: 2 \mathrm{n}-6 /$ metabolites below that of the diabetic (CTL) mice (1.56 v. $1.77, P<0.05$ ). The decrease in 18:2n-6/metabolites in the non-diabetic (SFO) or (EPO) mice suggests that the supplemental $18: 2 n-6$ was adequately metabolized in these mice. However, in the diabetic (SFO) mice, the ratio increased suggesting that $18: 2 n-6$ was not adequately metabolized. 18:3n-6 (the immediate desaturase metabolite of $18: 2 n-6$ ) in the EPO could be further metabolized, thus proportionally increasing $20: 4 n-6$ and $22: 5 n-6$, and lowering 18:2n-6/metabolites in the pancreas of the diabetic (EPO) mice (Table 3). HCO supplementation of the diabetic mice had no effect on the $18: 2 n-6 /$ metabolites in the pancreas.

One significant difference between the EFA changes in streptozotocin-induced diabetes and genetically induced diabetes is the percentage composition of $18: 2 n-6$ and $20: 4 n-6$ in the skin; in the former, $18: 2 n-6$ decreases and $20: 4 n-6$ increases significantly suggesting enhanced 18:2n-6 desaturation (Huang et al. 1984) whereas, in the latter, $18: 2 n-6$ is unchanged and 20:4n-6 decreased (Table 6). Whether the difference in the skin fatty acid composition of the diabetic and non-diabetic mice in the present study can be related to the significantly increased dermal thickness (see Plate 1) in the diabetic mice is unknown. 
Genetically obese mice (C57BL/6J) and diabetic mice are phenotypically similar; obesity, elevated plasma glucose and insulin levels occur in both. In some respects, the percentage EFA composition of their tissues is also similar; in the liver tPL of both the obese and diabetic mice, 18:3n-6, 22:5n-6 and 18:3n-3 were not detectable, $20: 3 n-6$ was elevated and 22:4n-6 was decreased (Table 4, Cunnane et al. 1985). Similarly, in the liver TG of both obese and diabetic mice, 18:3n-6, 20:3n-6, 20:4n-6 and 22:6n-3 were low compared with those of non-diabetic or lean mice. However, after supplementation with HCO, SFO or EPO, proportionally, 20:4n-6 in the liver tPL of the obese mice decreased slightly but, in the diabetic mice, it increased significantly. After EFA supplementation, the obese mice accumulated proportionally more $18: 2 \mathrm{n}-6$ in the liver TG and less $18: 3 n-6,20: 3 n-6$ and $20: 4 n-6$ than did the diabetic mice. In contrast to the diabetic mice, however, the obese mice had proportionally lower total $\mathrm{n}-3$ EFA.

In conclusion, we have observed that the altered EFA composition in the tissue lipids of diabetic mice can be partially corrected by supplementation with SFO or, more effectively, with EPO. However, two of the features which characterize these mice as insulin-independent diabetic animals, obesity and elevated plasma glucose, were not significantly improved in mice supplemented with EFA. The possible relation between EFA and genetic diabetes in mice, therefore, remains unclear.

S.C.C. gratefully acknowledges receipt of a National Research Council (Canada) Industrial Research Fellowship during the tenure of this work. Histological sections were prepared at the Pathology Laboratory, Blanchard Fraser Memorial Hospital, Kentville, Novia Scotia. Dr R. Drummond kindly prepared the photomicrographs. Excellent technical assistance was provided by M. A. Ryan, N. Morse and V. Kyte.

\section{REFERENCES}

Brenner, R. R. (1977). Advances in Experimental Biology and Medicine 83, 85-102.

Brenner, R. R., Peluffo, R. O., Mercuri, O. \& Restelli, M. A. (1968). American Journal of Physiology 215, 63-69. Clark, D. L., Hamel, F. G. \& Queener, S. F. (1983). Lipids 18, 696-705.

Coleman, D. L. (1981). In Mammalian Genetics and Cancer: The Jackson Laboratory Fiftieth Anniversary Symposium, pp. 145-158. New York: A. R. Liss.

Coleman, D. L. \& Hummel, K. P. (1967). Diabetologia 3, 238-248.

Cunnane, S. C., Manku, M. S. \& Horrobin, D. F. (1985). British Journal of Nutrition. 53, 441-448.

De Alaniz, M. J. T. \& Brenner, R. R. (1969). Acta Physiologica Latinoamericana 19, 1-15.

Faas, F. H. \& Carter, W. J. (1980). Lipids 15, 953-961.

Faas, F. H. \& Carter, W. J. (1983). Lipids 18, 339-342.

Futterman, S. \& Kupfer, C. (1968). Investigative Ophthalmology 7, 105-108.

Holman, R. T., Johnson, S. B., Gerrard, J. M., Mauer, S. M., Kupcho-Sandberg, S. \& Brown, D. M. (1983). Proceedings of the National Academy of Science, USA 80, 2375-2379.

Houtsmuller, A. J., van Hal-Ferwerda, J., Zahn, K. J. \& Henkes, H. E. (1980). Nutrition and Metabolism 24 (Suppl. 1), 105-108.

Houtsmuller, A. J., van Hal-Ferwerda, J., Zahn, K. J. \& Henkes, H. E. (1981). Progress in Lipid Research 20, 377-386.

Huang, Y.-S., Horrobin, D. F., Manku, M. S., Mitchell, J. \& Ryan, M. A. (1984). Lipids 19, 367 370.

Jones, D. B., Carter, R. D., Haitas, B. \& Mann, J. I. (1983). British Medical Journal 286, 173-175.

Laychock, S. (1983). Diabetes 32, 6-13.

Mercuri, O., Peluffo, R. O. \& Brenner, R. R. (1966). Biochimica et Biophysica Acta 116, 406-411.

Poisson, J. P., LeMarchal, P., Blond, J. P., Lecerf, J. \& Mendy, F. (1978). Diabetes and Metabolism 4, $39-45$.

Pratt, J. D. (1984). Hormone and Metabolic Research 16, 152-153. 
EXPLANATION OF PLATE

Cross-sections through the skin of $(a)$ diabetic and $(b)$ non-diabetic mice. Sections were stained with haematoxylineosin and photomicrographs were taken at $\times 900$. The dermal layer is, on average, three times thicker in the skin of the non-diabetic mice. Supplementation with hydrogenated coconut oil, safflower oil or evening primrose oil did not affect the difference in dermal thickness between the two groups. 

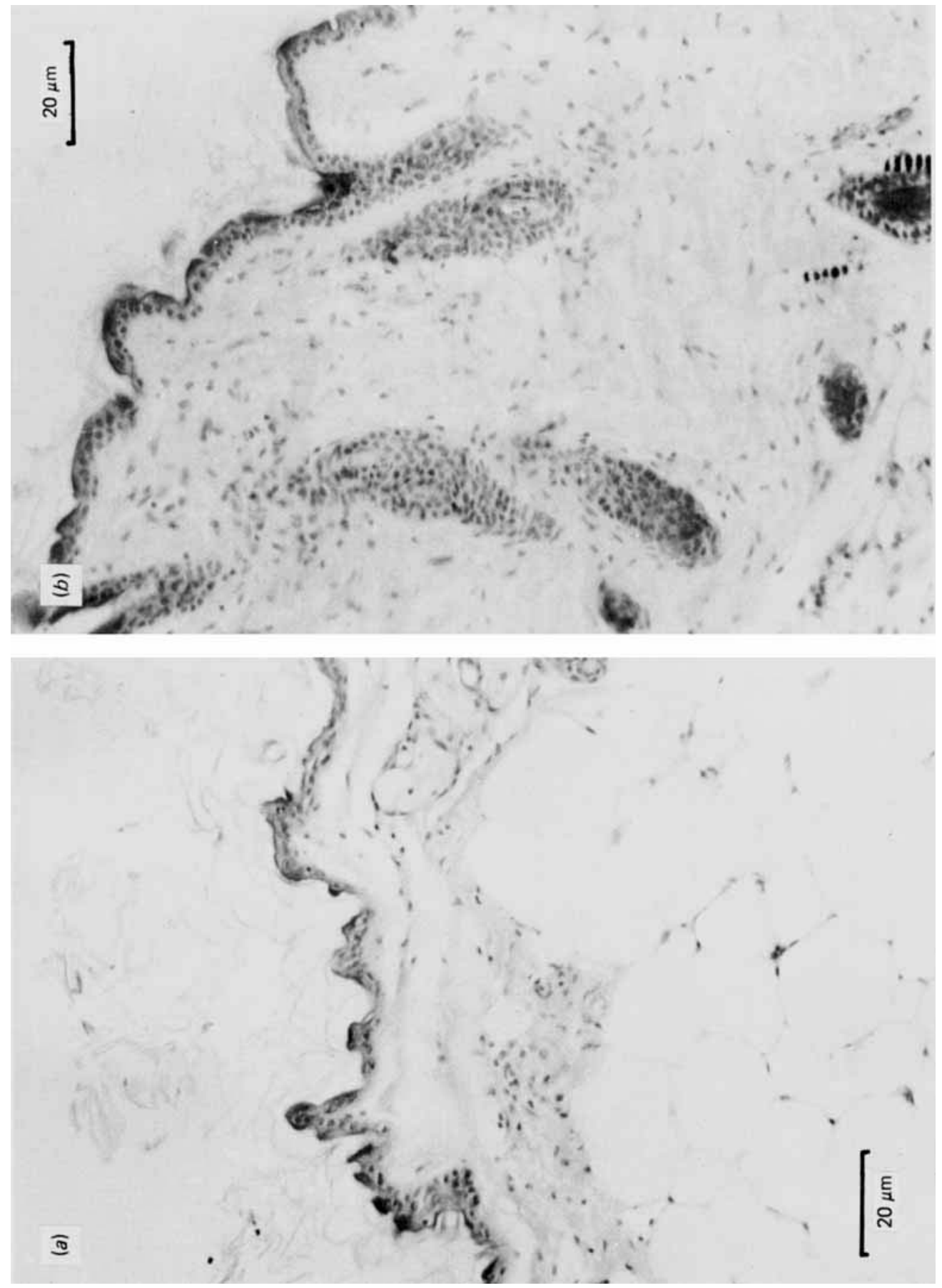